\title{
SURGICAL SITE INFECTION AFTER CESAREAN SECTION IN UKRAINE: RESULTS A MULTICENTER STUDY
}

DOI: 10.36740/WLek202104123

\author{
Aidyn G. Salmanov' , Alla D. Vitiuk', Oleg M. Ishchak1,2, Kateryna S. Insarova', Serhii L. Chyrva ${ }^{3}$, \\ Marina L. Kuzomenska ${ }^{3}$, Oleg V. Golianovsky ${ }^{1}$ \\ 'SHUPYK NATIONAL HEALTHCARE UNIVERSITY OF UKRAINE, KYIV, UKRAINE \\ 2TERNOPIL PERINATAL CENTER, TERNOPIL, UKRAINE \\ 'SUMY STATE UNIVERSITY, SUMY, UKRAINE
}

\begin{abstract}
The aim: To obtain the first national estimates of the current prevalence rate of SSI after CSEC and antimicrobial resistance of causing pathogens in Ukraine.

Materials and methods: We performed a retrospective multhicentre cogort study based surveillance data was conducted from May 2017 to December 2019 . The study population consisted of all women who had a cesarean section in 11 regional women hospitals of Ukraine. Definitions of SSI after cesarean section were used from the CDC/ NHSN. Results: A total of 2326 CSEC operations and 14.7\% SSI were identified within 30 days of the operation. Of these, $44.4 \%$ were superficial incisional SSI, $28.9 \%$ were deep incisional SSI, and $26.6 \%$ were organ/space SSI, $25.7 \%$ of which were classed as endometritis. Of all cases $70.5 \%$ of infections were detected post discharge. The most commonly identifed pathogen were Staphylococcus aureus (23.5\%), Escherichia coli (20\%), Coagulase-negative staphylococci (8.1\%), Enterococcus spp. (7.7\%), Pseudomonas aeruginosa (7.7\%), Enterobacter spp. (6.4\%), and Streptococcus spp. (5.6\%). The overall proportion of extended spectrum beta-lactamase(ESBL) production among Enterobacteriaceae was $18.3 \%$ and of methicilin-resistance in S. aureus (MRSA) $13.9 \%$. Resistance to third-generation cephalosporins was observed in 15.2\% E.coli and 7.9\% Klebsiella pneumoniae isolates. Carbapenem resistance was identified in 7.3\% of P.aeruginosa isolates. Conclusions: The results of this study revealed high rates of SSI after CSEC and most causing pathogens were associated with resistant to antibiotic stranis. This knowledge is essential to develop targeted strategies to surveillance and reduce the incidence of postoperative infections.
\end{abstract}

KEY WORDS: Surgical site infection, cesarean section, antimicrobial resistance, pathogens, Ukraine

Wiad Lek. 2021;74(4):934-939

\section{INTRODUCTION}

Cesarean section (CSEC) is one of the most common surgical procedures performed in the both developed and developing countries [1]. Caesarean delivery in the United States accountsfor $32 \%$ of all births [2]. In 2017, CSEC in the European Union (EU) was performed at least 1.4 million times. Among the EU Member States, caesareans were most frequent in Cyprus (54.8\%), Romania (44.1\%), Bulgaria (43.1\%), Poland (39.3\%) and Hungary (37.3\%) [3]. Similarly, high CSEC rates have been reported in the Australia and China, where 32.4\% and 41\% of births are by CSEC, respectively $[4,5]$. CSEC in Ukraine accounts for up to $23 \%$ of all births.

As with any surgery, CSEC can be associated with surgical site infections (SSIs). Postpartum SSI after CSEC is a major cause of long hospital stays and there is an increased cost burden on the public healthcare systems as well as to mothers and their families $[6,7]$. These infections are associated with high morbidity and mortality $[8,9]$ in women. Over the past two decades, along with significant improvements in clinical obstetric care in many countries, the incidence rate of SSIs after CSEC remains an important issue.

Current guidelines for management of SSI recommend the use of antibiotics as well for prevention, and as for both treatment postoperative infections. However, the growing antimicrobial resistance is limiting their use. Resistant SSI is becoming more and more pressing for medical specialists a worldwide. In the available literature, studies on antimicrobial resistance of infectious agents of SSIs after CSEC are limited. Monitoring of the prevalence of etiologic agents of SSIs after CSEC and antimicrobial resistance is necessary to enhance our knowledge of its epidemiology.

There is no surveillance system for SSI in Ukraine. Consequently, incidence rates of SSI after CSEC and antimicrobial resistance in Ukraine are currently unknown. This creates problems as well for physicians and as infection control professionals in Ukraine. To our knowledge, the prevalence of and causative agents of most SSIs among female in-patients have not been studies in Ukraine. This was the basis for our study.

\section{THE AIM}

The aim of this study was to obtain the first national estimates of the current prevalence rate of SSI after CSEC and antimicrobial resistance of causing pathogens in Ukraine.

\section{MATERIALS AND METHODS}

\section{SETTING AND PARTICIPANTS}

We performed a retrospective multicentre cohort study was based on surveillance data of SSI after CSEC in women's from 
Table I. Distribution of surgical site infections after caesarean section in the participating hospitals

\begin{tabular}{cccc}
\hline Hospital & No. of operations & No. of SSIs & $\begin{array}{c}\text { Incidence of SSIs per 100 } \\
\text { operations [95\% CI] }\end{array}$ \\
\hline A & 218 & 29 & $13.3[11.0-15.6]$ \\
\hline B & 211 & 25 & $11.8[9.6-14.0]$ \\
\hline C & 203 & 22 & $10.8[8.6-13.0]$ \\
\hline D & 229 & 56 & $24.5[21.7-27.3]$ \\
\hline E & 208 & 19 & $9.1[7.1-11.1]$ \\
\hline F & 212 & 29 & $13.7[11.3-16.1]$ \\
\hline G & 218 & 31 & $14.2[11.8-16.4]$ \\
\hline H & 227 & 43 & $18.9[16.3-21.5]$ \\
\hline I & 193 & 22 & $11.4[9.2-13.6]$ \\
\hline J & 206 & 27 & $13.1[10.8-15.4]$ \\
\hline K & 201 & 39 & $19.4[16.7-22.1[$ \\
\hline Total & 2326 & 342 & $14.7[14.0-15.4]$ \\
\hline
\end{tabular}

January 1st, 2017 to December 31st, 2019 in 11 regional (tertiary) women hospitals of Ukraine. The hospitals had 1850 beds. They are similar in terms of medical equipment, staff and number of beds. Women hospitals were required to have at least one full-time infection-control professional and clinical microbiology laboratory. Only hospitals that provided data using the same surveillance option (patient-based) for at least three years were included in the study.

The study population included 2,326 women aged 20-51 years who underwent cesarean delivery from 2017 to 2019 in 11 regional women hospitals in Ukraine. All women who underwent caesarean section within the 30 day follow-up period met the inclusion criteria and were included in the study cohort. All participants were local residents.

\section{DEFINITIONS AND DATA COLLECTION}

Diagnosis of SSIs after CSEC was based on criteria from the CDC/NHSN Surveillance Definitions for Specific Types of Infections [10]. In this study, we analyzed the inpatient data and ambulatory medical records to identify SSIs after CSEC procedures. The surveillance protocol and dataset were based on the CDC/NHSN criteria. We collected the data (demographic and clinical data, microbiology, and outcome information from hospital and outpatient records) using structured CDC/NHSN Checklist. Cases of SSIs that met standard case definitions were identified through active follow up during the hospital stay, on return to hospital, and during visits to ambulatory. The surveillance period for the patients after CSEC was 30 days.

\section{MICROBIOLOGICAL METHODS}

All samples were obtained from women with clinical symptoms of SSI. Microbial isolates were identified using standard microbiological techniques, including automated microbiology testing (Vitek-2; bioMe' rieux, Marcyl'Etoile, France). Antibiotic susceptibility testing was performed by using the disk diffusion method (Kirby - Bauer antibiotic testing) according to the recommendations of the European Committee on Antimicrobial Susceptibility Testing (EUCAST). Strains in the intermediate range were classified as resistant for data analysis.

\section{ETHICS}

The Shupyk National Healtcare University of Ukraine Ethics Committee approved the waiver of informed consent to participate in this study due to its retrospective design. All participants data were anonymised prior to the analysis.

\section{STATISTICAL ANALYSIS}

For surgical procedure (CSEC) under surveillance, were calculated the percentage of SSIs per 100 operations: an indicator which includes both SSIs diagnosed during hospital stay and after discharge from the hospital (detected at hospital readmission or by post-discharge surveillance). Prevalence of SSIs after CSEC was reported as the percentage of the total number of women who had cesarean procedure. We analyzed samples from women's in the context of a study about microbiology of SSI after CSEC and antimicrobial resistance of responsible pathogens. The analysis of statistical data was performed using Excel. Comparisons were undertaken using Student's t-test and Fisher's exact test for categorical variables. Statistical significance was defined as $P<0.05$.

\section{RESULTS}

\section{PREVALENCE OF SSI}

During the study period (2017-2019) applying all methods of detection, a total of 342 SSIs were identified from 2326 cesarean procedures. The prevalence of SSI after CSEC in Ukraine was $14.7 \%$ [ $95 \%$ confidence interval 
Aidyn G. Salmanov et al.

Table II. Characteristics of patients with SSI after cesarean delivery in Ukraine $(\mathrm{P}<0.05)$

\begin{tabular}{|c|c|c|c|c|}
\hline \multirow{2}{*}{ Variables } & \multirow{2}{*}{$\begin{array}{l}\text { Number of participants } \\
n\end{array}$} & \multicolumn{2}{|c|}{ SSI ${ }^{\mathrm{a}}$} & \multirow{2}{*}{$95 \% \mathrm{Cl}^{\mathrm{b}}$} \\
\hline & & $\mathbf{n}$ & $\%$ & \\
\hline \multicolumn{5}{|c|}{ Age of participants } \\
\hline$\leq 20$ & 117 & 13 & 11.1 & $10.4-11.7$ \\
\hline $21-25$ & 276 & 42 & 15.2 & $14.5-15.9$ \\
\hline $26-30$ & 417 & 53 & 12.7 & $12.0-13.4$ \\
\hline $31-35$ & 436 & 57 & 13.1 & $12.4-13.8$ \\
\hline $36-40$ & 408 & 68 & 16.7 & $15.9-17.5$ \\
\hline $41-45$ & 261 & 35 & 13.4 & $12.7-14.1$ \\
\hline $46-50$ & 233 & 41 & 17.6 & $16.8-17.6$ \\
\hline$\geq 51$ & 178 & 33 & 18.5 & $17,7-19.3$ \\
\hline Total & 2326 & 342 & 14,7 & $14.0-15.4$ \\
\hline
\end{tabular}

Note

aSSI, Surgical site infection

bCl, confidence interval.

Table III. Distribution of microorganisms identified in SSIs following cesarean section in women hospitals (Ukraine, 2017-2019)

\begin{tabular}{|c|c|c|}
\hline Microorganisms & $\begin{array}{c}\text { All isolates } \\
(n=534)\end{array}$ & Percentages, \% \\
\hline Gram-positive cocci & 247 & 46.3 \\
\hline Staphylococcus aureus & 124 & 23.2 \\
\hline Coagulase-negative staphylococci & 43 & 8.1 \\
\hline Enterococcus species & 41 & 7.7 \\
\hline Streptococcus species & 30 & 5.6 \\
\hline Other Gram-positive cocci & 9 & 1.7 \\
\hline Gram-negative bacilli, Enterobacteriaceae & 194 & 36.3 \\
\hline Escherichia coli & 107 & 20.0 \\
\hline Citrobacter species & 7 & 1.3 \\
\hline Enterobacter species & 34 & 6.4 \\
\hline Klebsiella pneumoniae & 19 & 3.6 \\
\hline Proteus species & 16 & 3.0 \\
\hline Serratia species & 4 & 0.7 \\
\hline Other Enterobacteriaceae & 7 & 1.3 \\
\hline Gram-negative non- fermentative bacilli & 73 & 13.7 \\
\hline Acinetobacter species & 21 & 3.9 \\
\hline Pseudomonas aeruginosa & 41 & 7.7 \\
\hline Stenotrophomonas maltophilia & 5 & 0.9 \\
\hline Other gram-negative non-fermentative bacilli & 6 & 1.1 \\
\hline Anaerobes & 15 & 2.8 \\
\hline Bacteroides species & 5 & 0.9 \\
\hline Other anaerobes & 10 & 1.9 \\
\hline Fungi & 5 & 0.9 \\
\hline Candida species & 5 & 0.9 \\
\hline
\end{tabular}

(CI) 14.0-15.4]. Of these, 152 (44.4\%) were superficial incisional SSI, 99 (28.9\%) were deep incisional SSI, 91 (26.6\%) were organ/space SSI, $25.7 \%$ of which were classed as endometritis.
Of all cases $29.5 \%(101 / 342)$ of infections were detected in during the admission period and $70.5 \%(241 / 342)$ were detected post discharge. The incidence rates of SSI were $10.7 \%$ [95\% CI 10.1 - 11.3] after elective cesarean delivery 
and $18 \%$ [95\% CI $17.2-18.8]$ after urgent cesarean section. None of the patients died as a result of SSIs after CSEC procedure. The incidence of SSIs after caesarean section in the participating hospitals varied significantly (Table I).

In this study the median time the duration admission period for all surgical site infections was 7 days and for deep and organ/space infections alone was 9 days. The median age of women included in the study was 31 years (range 20-51). Characteristics of a cohort of women's had cesarean delivery admitted to the regional women's hospitals of Ukraine are presented in Table II.

\section{ANTIBIOTIC PROPHYLAXIS}

In this study $95.9 \%(2231 / 2326)$ of women for whom information was collected were given antimicrobial prophylaxis. In most hospitals (8/11) the first choice of antibiotic agent was cefazoline or cefotaxim. A further four hospitals used ceftriaxone. Of 2326 cesarean delivery participants who underwent chart review, $83.7 \%$ were prescribed combination ceftriaxone and metronidazole postpartum. Ceftriaxone and metronidazole was also prescribed for $71.9 \%$ participants meeting criteria for SSIs, and $28.1 \%$ were prescribed alternative antibiotic regimens. During the study period, there were two maternal deaths in hospitals, none of which were due to infection.

\section{CAUSING PATHOGENS AND ANTIMICROBIAL RESISTANCE}

A total of 534 different bacterial strains were isolated from 342 women are with SSIs. Causative microorganisms were recorded for all of the infections. Of these infections $56.1 \%$ $(192 / 342)$ were reported to be polymicrobial. Aerobic gram-negative bacilli make up 50\% and $46.3 \%$ gram-positive cocci from of all isolates. The most commonly identifed pathogen were Staphylococcus aureus (23.5\%), Escherichia coli (20\%). Other pathogens included Coagulase-negative staphylococci (8.1\%), Enterococcus spp. (7.7\%), Pseudomonas aeruginosa (7.7\%), Enterobacter spp. (6.4\%), and Streptococcus spp. (5.6\%) as shown in Table III.

In this study among the atibiotics tested, the ertapenem and piperacillin/tazobactam, and cefotaxim were the most consistently active against Enterobacteriaceae. The overall proportion of extended spectrum beta-lactamase (ESBL) production among Enterobacteriaceae was $18.3 \%$ and of methicillin-resistance in S. aureus (MRSA) 13.9\%. Against P. aeruginosa, the carbapenems (meropenem, ertapenem), and trimethroprim/ sulfamethoxazole were the most active agents in infection cases. Vancomycin, teicoplanin, linezolid and fosfomycin, were the most consistently active to the strains of Enterococcus spp. Resistance to third-generation cephalosporins was observed in $15.2 \%$ E.coli and $7.9 \%$ K. pneumoniae isolates. Carbapenem resistance was identified in $7.3 \%$ of P.aeruginosa isolates.

\section{DISCUSSION}

This study present the first national estimates of the current prevalence rate of SSI (incisional and organ / space) after
CSEC in Ukraine using criteria from the CDC/NHSN (USA). The results of SSI surveillance presented in this study constitute a useful source of information on SSIs following CSEC in the participating women hospitals in 2017-2019. A total of 2326 CSEC operations and 14.7\% SSI were identified within 30 days of the operation. Of these, $44.4 \%$ were superficial incisional SSI, $28.9 \%$ were deep incisional SSI, and $26.6 \%$ were organ/space SSI. Of all cases $70.5 \%$ of infections were detected post discharge.

The incidence of SSI after CSEC is was 7-10\% [11-13]. In European Union Member States for CSEC operations, the percentage of SSIs was $2.2 \%$, with an inter-country range from $0.6 \%$ to $7.7 \%$ [14]. The percentages of SSIs for CSEC operations in the Ukraine were significantly higher than those reported from EU for 2014-2016 [14] and other countries [11-13]. Perhaps this is due to the use of various methods for definitions of SSIs and the timing of the postoperative surveillance period. In the present study, most of the patients with SSI were diagnosed after discharge from the hospital which is consistent with literature data [15-19].

In the present study, the most frequently identified causing pathogens of SSIs following CSEC were $S$. aureus and Escherichia coli, which is consistent with other studies $[14,20,21]$. Other pathogens included Coagulase-negative staphylococci, Enterococcus spp., P. aeruginosa, Enterobacter spp., and Streptococcus spp.[21]. The overall proportion of extended spectrum beta-lactamase (ESBL) production among Enterobacteriaceae was $18.3 \%$ and of methicillin-resistance in S. aureus (MRSA) 13.9\%. Resistance to third-generation cephalosporins was observed in $15.2 \%$ E.coli and $7.9 \%$ Klebsiella pneumoniae isolates. Carbapenem resistance was identified in $7.3 \%$ of P.aeruginosa isolates. According to literature [22-24] and our local antibiotic therapy guidelines, SSIs can be prevented or the rates reduced by including appropriate preoperative antibiotic prophylaxis. However, despite the use of prophylactic antibiotics $14.7 \%$ of our patients developed SSI. Perhaps this is due to the high level of antimicrobial resistance of infectious agents that were identified in our study.

\section{STRENGTHS AND LIMITATION}

The present study is first step is to quantify this burden for the first time and estimate of the incidence of SSI following CSEC in Ukraine. The strengths of the study lie in the application of CDC/NHSN methodology. The diagnosis of SSI after CSEC based on the CDC / NHSN criteria and where the surveillance period is 30 days. A limitation of the study is that it only include $11(45.8 \%)$ from 24 regional women's hospitals in Ukraine. The results this study may not be representative of other regional women hospitals of Ukraine with different distributions of incidence rate of SSIs after CSEC and antimicrobial resistance of causing pathogens.

\section{CONCLUSIONS}

The results of this study revealed high rates of SSI after CSEC and most causing pathogens were associated with resistant to 
antibiotic stranis. The most SSI following CSEC is detected after patient's discharge from the hospital. Urgent cesarean operation and improper antibiotic prophylaxis are important risk factors in the development of SSI. This knowledge is essential to develop targeted strategies to surveillance and reduce the incidence of postoperative infections. Further research is required to determine which set of interventions optimize prevetion of SSI after CSEC and improvement in patient outcomes.

\section{REFERENCES}

1. WHO Statement on Caesarean Section Rates. https://apps.who. int/iris/bitstream/handle/10665/161442/WHO_RHR_15.02_eng. pdf? sequence $=1$.

2. Kawakita T., Landy H.J. Surgical site infections after cesarean delivery: epidemiology, prevention and treatment. Matern Health Neonatol Perinatol. 2017; 3: 12. doi: 10.1186/s40748-017-0051-3.].

3. Eurostat. Caesarean births in the EU Member States. https://ec.europa. eu/eurostat/web/products-eurostat-news/-/DDN-20191217-1.

4. LiZ.,Zeki R., Hilder L., Sullivan E.A. Australia's mothers and babies 2011. Perinatal statistics series no. 28. Cat. no. PER 59. Canberra: AlHW National Perinatal Epidemiology and Statistics Unit. 2013. https://www.aihw. gov.au/getmedia/265f3a72-1ea2-4bff-8a44-b16ca55d00f4/15639. pdf.aspx?inline=true.

5. Betran A.P., Merialdi M., Lauer J.A. et al. Rates of caesarean section: analysis of global, regional and national estimates. Paediatr Perinat Epidemiol .2007;21:98-113. doi:10.1111/j.1365-3016.2007.00786.x.

6. Blumenfeld Y.J., El-Sayed Y.Y., Lyell D.J. et al. Risk factors for prolonged postpartum length of stay following cesarean delivery. Am J Perinatol. 2015;32(9):825-832. doi: 10.1055/s-0034-1543953.

7. Jenks P.J., Laurent M., McQuarry S. et al. Clinical and economic burden of surgical site infection (SSI) and predicted financial consequences of elimination of SSI from an English hospital. J Hosp Infect. 2014;86:2433. doi:10.1016/j.jhin.2013.09.012.

8. Pierson R.C., Scott N.P., Briscoe K.E., Haas D.M. A review of postcaesarean infectious morbidity: how to prevent and treat. J Obstet Gynaecol. 2018;38(5):591-597.doi: 10.1080/01443615.2017.1394281.

9. Goepfert A.R., Guinn D.A., Andrews W.W. et al. Necrotizing fasciitis after cesarean delivery. Obstet Gynecol. 1997;89(3):409-412. doi: 10.1016/ S0029-7844(96)00511-X.

10. Horan T.C., Andrus M., Dudeck M.A. CDC/NHSN surveillance definition of health care-associated infection and criteria for specific types of infections in the acute care setting. Am J Infect Control. 2008;36(5):309332. doi:10.1016/j.ajic.2008.03.002.

11. Centers for Disease Control Surgical Site Infection (SSI) Event. 2018. https://www.cdc.gov/nhsn/pdfs/pscmanual/9pscssicurrent.pdf.

12. Yokoe D.S., Christiansen C.L., Johnson R. et al. Epidemiology of and surveillance for postpartum infections. Emerg Infect Dis 2001;7:837-841.

13. Conner S.N., Verticchio J.C., Tuuli M.G. et al. Maternal obesity and risk of postcesarean wound complications. Am J Perinatol 2014;31:299-304.

14. European Centre for Disease Prevention and Control. Annual Epidemiological Report 2016. Surgical site infections. Stockholm: ECDC. 2016. https://www.ecdc.europa.eu/en/publications-data/surgical-siteinfections-annual-epidemiological-report-2016-2014-data.

15. Ward V.P., Charlett A., Fagan J. et al. Enhanced surgical site infection surveillance following caesarean section: experience of a multicentre collaborative post-discharge system. J Hosp Infect. 2008;70(2):166-73. doi: 10.1016/j.jhin.2008.06.002.
16. Barbut F., Carbonne B., Truchot F. et al. Surgical site infections after cesarean section: results of a five-year prospective surveillance. J Gynecol Obstet Biol Reprod (Paris).2004;33(6Pt 1):487-96. doi:10.1016/50368-2315(04)96561-1.

17. Mitt P., Lang K., Peri A. et al. Surgical-site infections following cesarean section in an Estonian university hospital: postdischarge surveillance and analysis of risk factors. Infect Control Hosp Epidemiol. 2005; 26(5):449-54. doi: 10.1086/502566.

18. Johnson A., Young D., Reilly J. Caesarean section surgical site infection surveillance. J Hosp Infect. 2006;64(1):30-5. doi: 10.1016/j. jhin.2006.03.020.

19. Reilly J., Allardice G., Bruce J. et al. Procedure-specific surgical site infection rates and postdischarge surveillance in Scotland. Infect Control Hosp Epidemiol. 2006;27(12):1318-23. doi: 10.1086/509839.

20. Wloch C., Wilson J., Lamagni T. et al. Risk factors for surgical site infection following caesarean section in England: results from a multicentre cohort study. BJOG. 2012;119(11):1324-33. doi: 10.1111/j.14710528.2012.03452.x.

21. Zejnullahu V.A., Isjanovska R., Sejfija Z. et al. Surgical site infections after cesarean sections at the University Clinical Center of Kosovo: rates, microbiological profile and risk factors. BMC Infect Dis. 2019;19(1):752. doi: 10.1186/s12879-019-4383-7.

22. Committee opinion no. 465: antimicrobial prophylaxis for cesarean delivery: timing of administration. Obstet Gynecol. 2010;116(3):791792. doi: 10.1097/AOG.0b013e3181f68086.

23. Berríos-Torres S.I., Umscheid C.A., Bratzler D.W. et al. Healthcare Infection Control Practices Advisory Committee. Centers for Disease Control and Prevention Guideline for the Prevention of Surgical Site Infection, 2017. JAMA Surg. 2017;152(8):784-791. doi:10.1001/ jamasurg.2017.0904.

24. Smaill F.M., Grivell R.M. Antibiotic prophylaxis versus no prophylaxis for preventing infection after cesarean section. Cochrane Database Syst Rev. 2014;(10):CD007482. doi: 10.1002/14651858.CD007482.pub3.

We would like to thank all the nurses and physicians who contributed to the prevalence surveys.

This work is a fragment of a research study of the Scientific Research Laboratory of Shupyk National Medical Academy of Postgraduate Education (Kyiv, Ukraine). Title: The scientific justification for measures to combat the resistance of microorganisms to antimicrobial drugs in Ukraine on the "One Health" approaches. State Registration Number: 0120U101440. Study period: 2020-2022. This work was funded by the Ministry of Health of Ukraine according to the plan of that research study. The authors did not receive any financial support from the manufacturers of medical instruments and drugs.

\section{ORCID and contributorship:}

Aidyn G. Salmanov: 0000-0002-4673-1154 A,C,D,E,F

Alla D. Vitiuk: 0000-0003-0550-1076 ${ }^{B, C, D, F}$

Oleg M. Ishchak: $0000000296343635^{B, C, D, F}$

Insarova S. Kateryna: 0000-0002-5110-426X B,C, D,F

Serhii L. Chyrva: 0000-0002-2848-483 B, C, D, F

Marina L. Kuzomenska: 0000-0003-0997-3792 B, C, D, F

Oleg V. Golianovsky: 0000-0002-5524-4411 ${ }^{C, D, F}$

\section{Conflict of interest:}

The Authors declare no conflict of interest 


\section{CORRESPONDING AUTHOR}

Aidyn G. Salmanov

Shupyk National Healthcare University of Ukraine

9 Dorohozhytska St., 04112 Kyiv, Ukraine

tel: +380667997631

e-mail:mozsago@gmail.com

Received: 29.11 .2020

Accepted: 08.03 .2021

A - Work concept and design, B - Data collection and analysis, C - Responsibility for statistical analysis,

D-Writing the article, $\mathbf{E}$-Critical review, $\mathbf{F}$ - Final approval of the article 